\title{
Study of Platelet Indices in Type 2 Diabetic Patients and Its Correlation with Vascular Complications
}

\author{
Sushma K L* and Rangaswamy M \\ Department of Pathology, JSS medical college, Mysore, India
}

\section{ABSTRACT}

Background: Diabetes Mellitus is a metabolic syndrome characterized by hyperglycemia resulting in macrovascular and microvascular complications. Altered platelet morphology and functions have been linked with the pathological processes and high risk of vascular disease. Platelet indices (Mean platelet volume-MPV, Platelet distribution width-PDW, and Platelet large cell ratio-PLCR) are determinants of platelet functionality.

Methods: The aim of this study was to study the platelet indices (MPV, PDW, P-LCR) in type - 2 diabetic patients with vascular complications and compare them in diabetic patients without vascular complications. The present study was conducted on 70 diabetic patients with vascular complications and 70 diabetic patients without vascular complications for a period of one year and eight months in department of pathology, JSS hospital, Mysore. Patients were divided into cases and controls depending on the presence or absence of macrovascular complications (Myocardial infarction, stroke, peripheral arterial disease) and microvascular complications (retinopathy, nephropathy and neuropathy). Platelet indices (MPV, PDW, P-LCR) were measured using an Automated Blood Counter. FBS and HbA1C levels were collected from the clinical proforma.

Result: Platelet indices were significantly higher in diabetic patients with vascular complications compared to those without complications $[11.37 \pm 1.19 \mathrm{fL}$ vs $10.17 \pm 0.71 \mathrm{fL}(\mathrm{P}=0.0001), 13.90 \pm 2.99 \mathrm{fL}$ vs $11.28 \pm 1.55 \mathrm{fL}(\mathrm{P}=0.0001), 35.61 \pm 9.35 \%$ vs $26.14 \pm 5.79 \%(\mathrm{P}=0.0001)$ respectively].

Conclusion: The present study showed a significantly higher MPV, PDW and P-LCR in diabetic patients with vascular complications compared to those without complications. This indicates that elevated platelet indices could be the cause for vascular complications. Hence MPV, PDW, P-LCR can be used as simple and cost effective predictive parameters of platelet activation to monitor and predict the risk of vascular complications.

Keywords: Diabetes Mellitus, Platelet Indices, Mean Platelet Volume, Platelet Distribution Width, Platelet Large Cell Ratio

\section{Introduction}

Diabetes Mellitus is characterized by hyperglycemia resulting in micro and macrovascular complications affecting the nerves, kidneys, eyes, CVS etc. ${ }^{[1]}$ It is associated with varying degree of hyperglycemia accompanied with the biochemical alterations in carbohydrate, protein and lipid metabolism. ${ }^{[2]}$ The injurious effects of hyperglycemia are characterized as macrovascular and microvascular complications. Altered platelet morphology and functions have been linked with the pathological processes and high risk of vascular disease. ${ }^{[3]}$ The platelet indices - (Platelet - PLT, Mean platelet volume - MPV, Platelet distribution width - PDW and Platelet large cell ratio - PLCR) are the determinants of platelet functionality, among which increased mean platelet volume (MPV) and platelet distribution width (PDW) were found to be attributed in the causation of thromboembolic complications. ${ }^{[4,5]}$ It is also noted that the platelets with increased number and size possibly affect the platelet distribution width contributing in the pathogenesis of vascular complications. ${ }^{[6]}$ Hyperactivity of platelets have an important role in the initiation of thrombosis and atherosclerotic lesions. Larger platelets are more active enzymatically and metabolically and have a higher thrombotic ability as compared to the small sized platelets. ${ }^{[7]}$

Sustained hyperglycemia leads to alterations in the vessel wall leading to endothelial dysfunction and vascular lesions in diabetic complications. ${ }^{[8]}$ Formation of advanced glycation end products, activation of protein kinase $\mathrm{C}$ and disturbances in polyol pathways are the possible mechanisms by which increased glucose induces vascular abnormalities. ${ }^{[9]}$

Large platelets are younger, more active, aggregable, have denser granules and secrete

more pro - aggregatory molecules. ${ }^{[10]}$ Platelet activation triggers thrombus formation and causes thromboembolism with release of PDGF and VEGF that accelerate the 
progression of vascular lesions. ${ }^{[11]}$ Increased platelet size may be one of the factor causing increased risk of atherosclerosis associated with diabetes mellitus and vascular complications. ${ }^{[12]}$

The aim of our study was to determine the hyperactivity of platelets in type 2 diabetic patients and its association with vascular complications. This was done by comparing the platelet indices- MPV, PDW and P-LCR, FBS and HbA1C levels among diabetic patients with vascular complications and diabetic patients without vascular complications.

\section{Materials and Methods}

This was an analytical study carried out on 70 type 2 diabetic patients having vascular complications and 70 type 2 diabetic patients without vascular complications for a period of one year and eight months in the department of pathology, JSS hospital, mysore. Data was collected fulfilling the inclusion and exclusion criteria.

Inclusion Criteria: Diabetic patients with vascular complications and diabetic patients without vascular

Exclusion Criteria : 1.) Non-diabetic patients with vascular complications \& 2.) Diabetics on antiplatelet drugs such as aspirin and clopidogrel.

Patients were divided into cases and controls depending on the presence or absence of macrovascular complications (Myocardial infarction , stroke, peripheral arterial disease) and microvascular complications (retinopathy, nephropathy and neuropathy). Platelet indices like MPV, PDW, P-LCR were measured in the above target groups using Automatic Blood Counter (SYSMEX, XN-1000). Venous blood samples collected in a vacutainer containing di-potassium EDTA were used. Samples were processed within one hour of collection and were maintained at room temperature. Plasma glucose levels and HbA1c levels of the patient were collected from the clinical data.

Statistical analysis was done using Statistical package for social sciences (SPSS version 22) software. Descriptive statistics such as numbers and percentages were used to describe categorical variables. Mean and standard deviations were used to describe continuous variables like MPV, PDW and P-LCR. Independent sample t-test was applied to find out the significant difference in MPV, PDW and P-LCR between the cases and controls. Pearsons correlation was used to analyse association between different variables. Statistical significance was determined at $5 \%$ level of significance (ie. $<0.05$ is significant). Microsoft word and Excel have been used to generate graphs, tables etc.

\section{Result}

Age of the diabetic patients who had complications ranged from 45 years 90 years with mean of $63.30 \pm 10.04$ ) years and age of the diabetic patients who did not have complications ranged from 48 years 86 years with mean of $61.29 \pm 8.89$ years. (table 2) There were 26 females and 44 males among cases and 32 females and 38 males among controls with Male to female ratio of $1.7: 1$. Duration of diabetes mellitus ranged from 5 years to $>20$ years in both the groups (cases and controls) with the mean duration being 15.97 \pm 4.42 . (table 2)

Among 70 cases, 55 (78.6\%) had macrovascular complications and 15 (21.4\%) had microvascular complications and among the patients with macrovascular complications, 29 (41.4\%) patients had cardiovascular complications, 18 (25.7\%) patients had Peripheral arterial diseases and 8 (11.4\%) patients had cerebrovascular complications. Among patients with microvascular complications, $11(15.7 \%)$ patients had Diabetic nephropathy, 3 (4.2\%) patients had Diabetic neuropathy and $1(1.4 \%)$ patient had Diabetic retinopathy. 70 controls did not have any complications. Among cases, 57 out of 70 patients $(81.4 \%)$ had FBS of $>126 \mathrm{mg} / \mathrm{dl}, 11$ out of 70 patients (15.7\%) had FBS between 100-126 mg/dl and 2 out of 70 patients $(2.8 \%)$ had FBS $<100 \mathrm{mg} / \mathrm{dl}$ with a mean of $208.53 \pm 79.67$. Among the controls, 43 out of 70 patients (61.4\%) had FBS of $>126 \mathrm{mg} / \mathrm{dl}, 16$ out of 70 patients $(22.8 \%)$ had FBS between $100-126 \mathrm{mg} / \mathrm{dl}$ and 11 out of 70 patients $(15.7 \%)$ had FBS $<100 \mathrm{mg} / \mathrm{dl}$ with a mean of 174.31 \pm 79.83. (table 1)

Among cases 68 out of 70 patients (97.1\%) had HbA1C levels of $\geq 6.5 \%$ and 2 out of 70 patients $(2.8 \%)$ had $\mathrm{HbAlC}$ levels of $<6.5 \%$ with a mean $\mathrm{HbA1C}$ levels of $9.58 \pm 2.0$. Among controls, 58 out of $70(82.8 \%)$ had HbA1C levels of $\geq 6.5 \%$ and 12 out of 70 patients $(17.1 \%)$ had HbA1C levels of $<6.5 \%$ with a mean HbA1C levels of $8.31 \pm 2.22$. (table 1)

Among the cases, 55 out of 70 patients (78.5\%) had a mean platelet volume of $\geq 10.5 \mathrm{fL}$ and 15 out of 70 patients (21.4\%) had an MPV of $<10.5 \mathrm{fL}$ with a mean of $11.377 \pm 1.1969$. Among the controls, 46 out of 70 patients (65.7\%) had MPV of $<10.5 \mathrm{fL}$ and 24 out of $70(24.2 \%)$ had MPV of $\geq 10.5 \mathrm{fL}$ with a mean of $10.173 \pm 0.7134$. (table 2). Among the cases, 49 out of 70 patients $(70 \%)$ had PDW of $\geq 12.5 \mathrm{fL}$ and 21 out of 70 patients (30\%) had a PDW of $<12.5 \mathrm{fL}$ with a mean PDW of $13.90 \pm 2.99$. Among the controls, 53 out of 70 patients (75.7\%) had PDW $<12.5 \mathrm{fL}$ and 17 out of 70 patients $(24.2 \%)$ had PDW of $\geq 12.5 \mathrm{fL}$ with a mean of $11.283 \pm 1.5501$. Among the cases, 54 out of 
70 patients $(77.1 \%)$ had P-LCR of $\geq 30.5 \%$ and 16 out of 70 patients $(22.8 \%)$ had a P-LCR of $<30.5 \%$ with a mean P-LCR of 35.617 \pm 9.3589 . Among the controls, 51 out of 70 patients $(72.8 \%)$ had P-LCR $<30.5 \%$ and 19 out of 70 patients $(27.1 \%)$ had P-LCR of $\geq 30.5 \%$ with a mean of $26.144 \pm 5.7915$.

A positive statistical Pearson correlation was seen among cases between PDW and Duration of diabetes mellitus ( $\mathrm{P}$ - 0.035) and FBS and HbA1c levels (P - 0.004). However, no statistical correlation was noted between MPV and age, duration of DM, FBS, HbA1C; PDW and age, FBS, HbA1C; P-LCR and age, duration of DM, FBS, HbA1C levels. (table 3) (Graph 1,2)

Among the controls, a positive statistical Pearson correlation was seen between MPV and HbA1c (P - 0.047), PDW and HbA1c (P - 0.003), P-LCR and HbA1c (P - 0.026) and FBS and HbA1c levels (P - 0.0001) (Graph 3). However, no statistical correlation was noted between MPV and age, duration of DM, FBS; PDW and age, duration of DM, FBS; P-LCR and age, duration of DM, FBS.

Table 1: Blood Glucose Parameters in Two Groups of Patients Studied.

\begin{tabular}{|c|c|c|c|c|}
\hline & \multicolumn{2}{|c|}{ CASES } & \multicolumn{2}{|c|}{ CONTROLS } \\
\hline & No. & $\%$ & No. & $\%$ \\
\hline \multicolumn{5}{|c|}{ FBS (mg/dl) } \\
\hline$<100$ & 2 & 2.8 & 11 & 15.7 \\
\hline $100-126$ & 11 & 15.7 & 16 & 22.8 \\
\hline$>126$ & 57 & 81.4 & 43 & 61.4 \\
\hline \multicolumn{5}{|l|}{$\mathrm{HbA1c}$} \\
\hline$<6.5$ & 2 & 2.8 & 12 & 17.1 \\
\hline$\geq 6.5$ & 68 & 97.1 & 58 & 82.8 \\
\hline
\end{tabular}

Table 2: MPV in Two Groups of Patients Studied.

\begin{tabular}{|l|c|c|c|c|}
\hline \multirow{2}{*}{ MPV } & \multicolumn{2}{|c|}{ Cases } & \multicolumn{2}{c|}{ Controls } \\
\cline { 2 - 5 } & No. & $\%$ & No. & 65.7 \\
\hline$<10.5$ & 15 & 21.4 & 46 & 34.2 \\
\hline$\geq 10.5$ & 55 & 78.5 & 24 & 100.0 \\
\hline Total & 70 & 100.0 & 70 & \\
\hline
\end{tabular}

Table 3: Comparison of Mean Platelet Volume (MPV)

\begin{tabular}{|l|c|c|c|}
\hline STUDY & MEAN MPV (fL) - CASES & MEAN MPV (fL) - CONTROLS & P - VALUE \\
\hline Agarwal BK et al (21) & $11 \pm 2.2$ & $7.8 \pm 1.3$ & 0.0001 \\
\hline Khandekar MM et al ${ }^{(15)}$ & $10.43 \pm 1.03$ & $9.2 \pm 0.91$ & 0.001 \\
\hline Sharma M et al(22) & $17.60 \pm 2.04$ & $9.93 \pm 0.64$ & $<0.001$ \\
\hline Khode V et al ${ }^{(23)}$ & $9.54 \pm 0.9$ & $9.21 \pm 0.6$ & 0.018 \\
\hline Present study & $11.377 \pm 1.1969$ & $10.173 \pm 0.7134$ & 0.0001 \\
\hline
\end{tabular}

Table 4 : PDW in Two Groups of Patients Studied.

\begin{tabular}{|l|c|c|c|c|}
\hline \multirow{2}{*}{ PDW } & \multicolumn{2}{|c|}{ Cases } & \multicolumn{2}{c|}{ Controls } \\
\cline { 2 - 5 } & No. & $\%$ & No. & 75.7 \\
\hline$<12.5$ & 21 & 30 & 17 & 24.2 \\
\hline$\geq 12.5$ & 49 & 70 & $\mathbf{7 0}$ & 100.0 \\
\hline Total & $\mathbf{7 0}$ & $\mathbf{1 0 0 . 0}$ & & $\mathbf{1 0}$ \\
\hline
\end{tabular}

Table 5: Comparison of Platelet Distribution Width (PDW).

\begin{tabular}{|l|c|c|c|}
\hline STUDY & MEAN PDW (fL) - CASES & MEAN PDW (fL) - CONTROLS & P - VALUE \\
\hline Khode V et al ${ }^{(23)}$ & $10.77 \pm 2.0$ & $10.35 \pm 1.3$ & 0.182 \\
\hline Jabeen F et al ${ }^{(2)}$ & $14.71 \pm 0.21$ & $13.86 \pm 0.297$ & 0.0269 \\
\hline Khandekar M et al ${ }^{(15)}$ & $13.19 \pm 2.34$ & $10.75 \pm 1.42$ & 0.001 \\
\hline Present study & $13.901 \pm 2.9995$ & $11.283 \pm 1.5501$ & $<0.0001$ \\
\hline
\end{tabular}


TABLE 6 : P-LCR in Two Groups of Patients Studied

\begin{tabular}{|l|c|c|c|c|}
\hline \multirow{2}{*}{ P-LCR } & \multicolumn{2}{|c|}{ Cases } & \multicolumn{2}{c|}{ Controls } \\
\cline { 2 - 5 } & No. & $\%$ & No. & 72.8 \\
\hline$<30.5$ & 16 & 22.8 & 19 & 27.1 \\
\hline$\geq 30.5$ & 54 & 77.1 & $\mathbf{7 0}$ & 100.0 \\
\hline Total & $\mathbf{7 0}$ & $\mathbf{1 0 0 . 0}$ & & $\mathbf{1 0}$ \\
\hline
\end{tabular}

Table 7: Comparison of Platelet Large Cell Ratio (P-LCR).

\begin{tabular}{|l|c|c|c|}
\hline STUDY & MEAN PLCR - CASES & MEAN P-LCR - CONTROLS & P - VALUE \\
\hline Khode $\mathrm{V}$ et al ${ }^{(23)}$ & $21.33 \pm 6.1$ & $19.93 \pm 4.6$ & 0.147 \\
\hline Khandekar M et al (15) & $29.4 \pm 7.38$ & $20.65 \pm 6.14$ & 0.001 \\
\hline Yilmaz T et al ${ }^{(24)}$ & $31.71 \pm 2.16$ & $28.59 \pm 2.28$ & $>0.05$ \\
\hline Present study & $35.617 \pm 9.3589$ & $26.144 \pm 5.7915$ & $<0.0001$ \\
\hline
\end{tabular}

Table 8: Comparison of Study Variables in Cases and Controls Studied.

\begin{tabular}{|l|c|c|c|}
\hline & $\begin{array}{c}\text { DIABETIC PATIENTS WITH } \\
\text { COMPLICATIONS }\end{array}$ & $\begin{array}{c}\text { DIABETIC PATIENTS } \\
\text { WITHOUT COMPLICATIONS }\end{array}$ & $\begin{array}{c}\text { P - VALUE } \\
\text { Age in years }\end{array}$ \\
\hline Duration of DM & $15.97 \pm 4.423$ & $61.29 \pm 8.88$ & 0.05 \\
\hline FBS $(\mathrm{mg} / \mathrm{dl})$ & $208.53 \pm 79.67$ & $12.36 \pm 3.04$ & 0.009 \\
\hline HbA1C in \% & $9.58 \pm 2.0$ & $174.31 \pm 79.83$ & 0.001 \\
\hline MPV $(\mathrm{fL})$ & $11.377 \pm 1.1969$ & $8.31 \pm 2.22$ & 0.0001 \\
\hline PWD $(\mathrm{fL})$ & $13.901 \pm 2.9995$ & $10.173 \pm 0.7134$ & 0.0001 \\
\hline P- LCR $(\%)$ & $35.617 \pm 9.3589$ & $11.283 \pm 1.5501$ & 0.0001 \\
\hline
\end{tabular}

Table 9: Pearson Correlation of MPV, PDW, PLCR and FBS with Study Variables in Cases and Controls.

\begin{tabular}{|l|c|c|}
\hline Pair & CASES (P - VALUE) & CONTROLS (P - VALUE) \\
\hline MPV vs Age in years & 0.388 & 0.176 \\
\hline MPV vs Duration of DM & 0.087 & 0.062 \\
\hline MPV vs FBS & 0.218 & $0.047^{*}$ \\
\hline MPV vs HbA1c & 0.483 & 0.157 \\
\hline PDW vs Age in years & 0.113 & 0.271 \\
\hline PDW vs Duration of DM & $0.035^{*}$ & 0.087 \\
\hline PDW vs FBS & 0.351 & $0.003^{*}$ \\
\hline PDW vs HbA1c & 0.326 & 0.120 \\
\hline P-LCR vs Age in years & 0.412 & 0.270 \\
\hline P-LCR vs Duration of DM & 0.115 & 0.077 \\
\hline P-LCR vs FBS & 0.309 & $0.026^{*}$ \\
\hline P-LCR vs HbA1c & 0.474 & $0.0001^{*}$ \\
\hline FBS vs HbA1c & $0.004^{*}$ & \\
\hline
\end{tabular}

* Statistically significant 


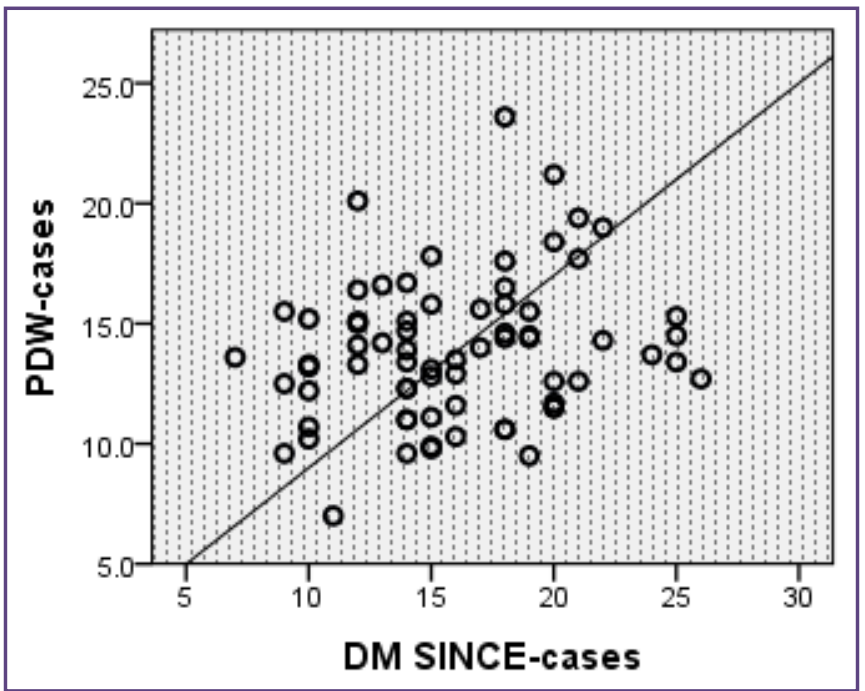

Graph 1: Scatterplot showing a positive correlation between platelet distribution width ( PDW) and duration of DM (P -0.035)

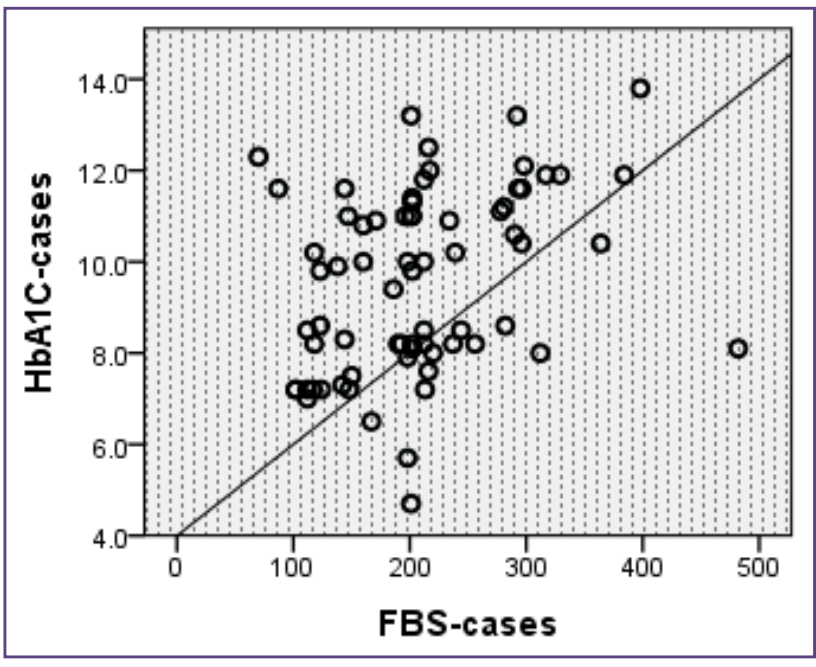

Graph 2: Scatterplot showing a positive correlation between FBS \& HbA1c (P - 0.004) - cases.

\section{Discussion}

Diabetes Mellitus is a metabolic syndrome characterized by hyperglycemia resulting in macrovascular and microvascular complications. Platelet hyperactivity has been linked with the pathological processes and high risk of vascular disease.

Platelet activation $\rightarrow$ platelet hyperactivity $\rightarrow$ thrombus formation $\rightarrow$ vascular complications

Platelet indices (MPV, PDW, PLCR) have been investigated as prospective platelet activation markers.

MPV is an indicator of average size and activity of platelets. Larger platelets are more active enzymatically and metabolically and have higher thrombotic ability as compared to small sized platelets which are depicted by

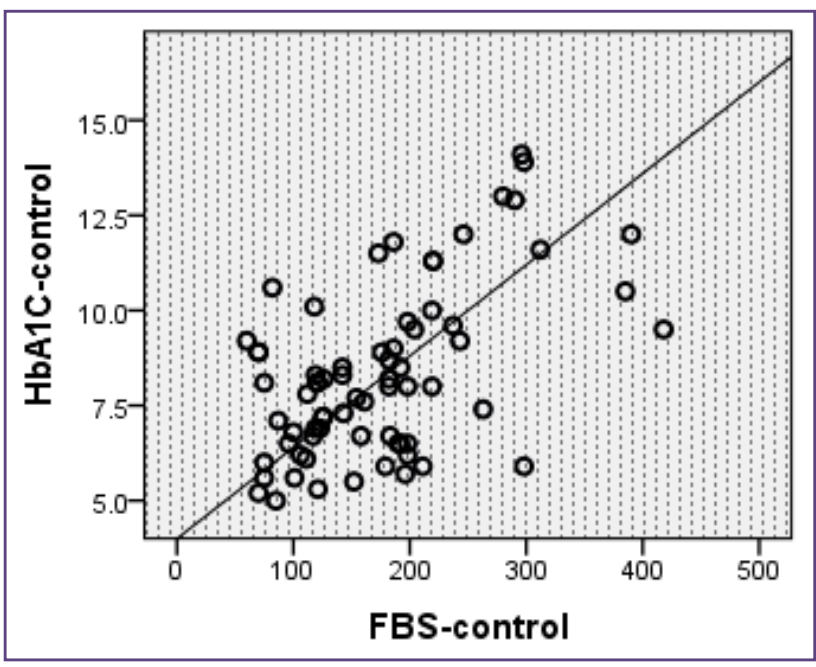

Graph 3: Scatterplot showing a positive correlation between FBS \&z HbA1c (P-0.0001) - controls.

increased MPV. Normal range - 7.5-11.5 fL. P-LCR is the increased percentage of large platelets. It is the ratio of large platelets from the $12 \mathrm{fL}$ discriminator or larger. Normal range - 11.9-66.9\%. PDW reflects how uniform the platelets are in size. Activated Platelets with increased number and size of pseudopodia differ in size, leading to alterations in platelet distribution width. Normal range of PDW is $8.3-25.0 \mathrm{fL}$.

Platelets play a pivotal role in atherothrombosis. ${ }^{[13]}$ Central to the pathogenesis of occlusive arterial disease is the activation of platelets at sites of vascular injury via pathologically exaggerated and dysregulated protective mechanisms of hemostasis. ${ }^{[14]}$ Platelets secrete and express a large number of substances that are crucial mediators of coagulation, inflammation, thrombosis and atherosclerosis. 
${ }^{[15,16]}$ Inadequate glycemic control, protein glycation and oxidative stress cause endothelial injury and platelet activation with altered platelet morphology and function leading to chronic complications in diabetics. ${ }^{[17]}$

The present study was done to determine if platelets are activated in diabetes and in its association with micro and macro-vascular complications.

Demographic Data: In the present study, the patients age ranged from 40 years to 90 years. The mean age of diabetic patients with vascular complications (cases) was higher compared to those without complications (controls) [63.30 \pm 10.04 vs $61.29 \pm 8.88]$ which correlated with the studies conducted by Jabeen $\mathrm{F}$ et $\mathrm{al}^{(2)}$ on various population. The maximum number of cases in this study were seen between the age of 50-69 years. Among the cases, 44 out of $70(62.9 \%)$ patients were males and 26 out of $70(37.1 \%)$ were females with male to female ratio of $1.7: 1$. This indicates that there was male preponderance in our study which correlated with the study conducted by Bath $\mathrm{P}$ et al ${ }^{[16]}$.

Duration of Diabetes: Duration of diabetes mellitus ranged from 5 years to $>20$ years in both the groups (cases and controls) in the present study with the mean duration being $15.97 \pm 4.42$. However other studies conducted by Alex kodiatte $\mathrm{T}$ et $\mathrm{al}^{[1]}$ and Dindar $\mathrm{S}$ et $\mathrm{al}^{\left[{ }^{[14]}\right.}$ showed a lesser mean duration.

Complications: Out of 70 cases, 55 (78.6\%) had macrovascular complications and 15 (21.4\%) had microvascular complications and among the patients with macrovascular complications, $29(41.4 \%)$ patients had cardiovascular complications, $18(25.7 \%)$ patients had Peripheral arterial diseases and $8(11.4 \%)$ patients had cerebrovascular complications.

Among patients with microvascular complications, 11(15.7\%) had Diabetic nephropathy, 3 (4.2\%) had Diabetic neuropathy and $1(1.4 \%)$ had Diabetic retinopathy. 70 controls did not have any complications.

Blood Glucose Parameters: Among cases, 57 out of 70 patients $(81.4 \%)$ had FBS of $>126 \mathrm{mg} / \mathrm{dl}, 11$ out of 70 patients (15.7\%) had FBS between 100-126 mg/dl and 2 out of 70 patients $(2.8 \%)$ had FBS $<100 \mathrm{mg} / \mathrm{dl}$ with a mean of $208.53 \pm 79.67$ which correlated with a study conducted by Ozder $\mathrm{A}$ et al ${ }^{(18)}$ and Ulutas et al. ${ }^{(19)}$. Among controls, 43 out of 70 patients $(61.4 \%)$ had FBS of $>126 \mathrm{mg} / \mathrm{dl}, 16$ out of 70 patients $(22.8 \%)$ had FBS between $100-126 \mathrm{mg} /$ $\mathrm{dl}$ and 11 out of 70 patients $(15.7 \%)$ had FBS $<100 \mathrm{mg} / \mathrm{dl}$ with a mean of $174.31 \pm 79.83$. In the present study, fasting blood sugar was significantly higher in cases compared to that of controls.

Among cases, 68 out of 70 patients (97.1\%) had HbA1C levels of $\geq 6.5 \%$ and 2 out of 70 patients $(2.8 \%)$ had HbA1C levels of $<6.5 \%$ with a mean HbA1C levels of $9.58 \pm 2.0$ which correlated with the studies conducted by Alex kodiatte $\mathrm{T}$ et $\mathrm{al}^{(1)}$, Sari $\mathrm{M}$ et $\mathrm{al}^{(20)}$ and Ozder A et al. ${ }^{(18)}$. Among controls, 58 out of 70 (82.8\%) had HbA1C levels of $\geq 6.5 \%$ and 12 out of $70(17.1 \%)$ had HbA1C levels of $<6.5 \%$ with a mean $\mathrm{HbA} 1 \mathrm{C}$ levels of $8.31 \pm 2.22$. In the present study the $\mathrm{HbA} 1 \mathrm{C}$ levels were significantly higher in cases compared to that of controls.

Platelet Indices: Among the cases, 55 out of 70 patients $(78.5 \%)$ had a mean platelet volume of $\geq 10.5 \mathrm{fL}$ and 15 out of 70 patients $(21.4 \%)$ had an MPV of $<10.5 \mathrm{fL}$ with a mean of $11.377 \pm 1.1969$ which correlated with the studies conducted by Agarwal BK et $\mathrm{al}^{(21)}$. Other studies showed a mean MPV lesser than the present study whereas one study conducted by Sharma $\mathrm{M}$ et $\mathrm{al}^{(22)}$ showed higher MPV than our study (table 2,3). Among controls, 46 out of 70 patients $(65.7 \%)$ had MPV of $<$ $10.5 \mathrm{fL}$ and 24 out of 70 (24.2\%) had MPV of $\geq 10.5 \mathrm{fL}$ with a mean of $10.173 \pm 0.7134$. Hence, the present study showed a significantly higher MPV in diabetic patients with vascular complications compared to diabetic patients without vascular complications $(\mathrm{P}<0.0001)$.

Activated platelets are larger, younger, more reactive and aggregable, have denser granules, secrete more pro - aggregatory molecules (serotonin, $\beta$ - thromboglobulin, thromboxane A2) which leads to thrombosis. This hypothesis has been well proved in our result which has shown an incease in MPV in diabetic patients with complications.

Among the cases, 49 out of 70 patients (70\%) had PDW of $\geq 12.5 \mathrm{fL}$ and 21 out of 70 patients $(30 \%)$ had a PDW of $<12.5 \mathrm{fL}$ with a mean PDW of $13.901 \pm 2.9995$ which correlated with studies conducted by Khandekar $M$ et $\mathrm{al}^{(15)}$. However, study conducted by Khode $\mathrm{V}$ et $\mathrm{al}^{(23)}$ showed PDW values lower than the present study (table 4,5). Among controls, 53 out of 70 patients $(75.7 \%)$ had PDW $<12.5 \mathrm{fL}$ and 17 out of 70 patients $(24.2 \%)$ had PDW of $\geq 12.5 \mathrm{fL}$ with a mean of $11.283 \pm 1.5501$. Hence, the present study showed a significantly higher PDW in diabetic patients with vascular complications compared to diabetic patients without vascular complications ( $\mathrm{P}$ $<0.0001)$. Activated Platelets with increased number and size of pseudopodia differ in size, leading to increase in platelet distribution width. 
Among the cases, 54 out of 70 patients (77.1\%) had P-LCR of $\geq 30.5 \%$ and 16 out of 70 patients $(22.8 \%)$ had a P-LCR of $<30.5 \%$ with a mean P-LCR of $35.617 \pm 9.3589$ but the other studies showed a lesser P-LCR than the present study (table 6,7). Among controls, 51 out of 70 patients $(72.8 \%)$ had P-LCR $<30.5 \%$ and 19 out of 70 patients $(27.1 \%)$ had P-LCR of $\geq 30.5 \%$ with a mean of $26.144 \pm 5.7915$. Hence, the present study showed a significantly higher P-LCR in diabetic patients with vascular complications compared to diabetic patients without vascular complications $(\mathrm{P}<0.0001)$.

Pearsons Correlation: A positive statistical Pearson correlation was seen among cases between PDW and Duration of diabetes mellitus $(\mathrm{P}-0.035)$ and FBS and HbA1c levels (P - 0.004). However, no statistical correlation was noted between other parameters. Among the controls, a positive statistical Pearson correlation was seen between MPV and HbA1c (P - 0.047), PDW and HbA1c (P - 0.003), $\mathrm{P}-\mathrm{LCR}$ and HbA1c (P - 0.026) and FBS and HbA1c levels (P-0.0001) (table 9).

\section{Conclusion}

Mean platelet volume (MPV), platelet distribution width (PDW) and platelet large cell ratio (P-LCR) are considered the important markers of platelet activation which can be easily measured as part of whole blood count. Hence MPV, PDW, P-LCR can be used as a simple and cost effective predictive parameters of platelet activation to monitor and predict the risk of vascular complications.

\section{Acknowledgements}

I express my sincere thanks and heartfelt gratitude to Dr. Jayashree K, Dr. Manjunath G.V, Dr. Suchitha S and Dr. Rajalakshmi B.R of the Department of Pathology for their support and guidance during this study. I express my most sincere regards and gratitude to my parents Mr. K. L Lokanatha, Mrs. K. L Lakshmi, my husband Dr. Anil Kumar G.V and my sister Mrs. Rashmi K. L for being a constant source of support. Last but not the least my heartfelt thanks to all the patients without whom this work would not have been possible.

\section{Reference}

1. Kodiatte T, Manikyam U, Rao S et al. Mean platelet volume in type 2 diabetes mellitus. J Lab Physicians. 2012;4(1):5-9.

2. Jabeen F, Fawwad A, Rizvi H et al. Role of platelet indices, glycemic control and hs-CRP in pathogenesis of vascular complications in type-2 diabetic patients. Pak J Med Sci. 2013;29(1):152-6.

www.pacificejournals.com/apalm
3. Park BJ, Shim JY, Lee HR, Jung DH, Lee JH, Lee YJ. The relationship of platelet count, mean platelet volume with metabolic syndrome according to the criteria of the American Association of Clinical Endocrinologists: A focus on gender differences. Platelets. 2012;23(1):45-50.

4. Cobon E, Bostan F, Ozdogan M. The mean Platelet volume in subjects with impaired fasting glucose. Platelet. 2006;17(1):67-69.

5. Winter WE, Signorino MR. Diabetes mellitus: pathophysiology, etiologies, Complications, management. J Clinical Chemistry. 2003;49(2):347.

6. Shera AS, Jawad F, Maqsood A, Jamal S, Azfar M, Ahmed U. Prevalence of chronic complications and associated factors in type 2 diabetes. J Pak Med Assoc. 2004;54(2):54-59.

7. Camur NK, Demirtunc R, Konuralp C, Eskiser A, Basaran Y. Could mean platelet volume be a predictive marker for acute myocardial infarction? Med Sci Monit. 2005;11(8):387-392.

8. Bae S, Lee J, Roh K et al. Platelet activation in patients with diabetic retinopathy. Korean J Ophthalmol. 2003;17:140-4.

9. Maitra A. The Endocrine System. In: Kumar V, Abbas AK, Fausto N, Aster JC, editors. Robbins and Cotran Pathologic Basis of Disease. 8th ed. New Delhi: Elsevier; 2010;1097164.

10. Mahsud MAJ, Khan A, Hussain J.Haematological changes in Tobacco using Type 2 diabetic patients. Gomal J Med Sci 2010;8:8-11.

11. Hekimsoy Z, Payzinb B, Ornek T et al. Mean Platelet Volume in Type 2 Diabetes Mellitus. J Diabetes complications. 2004;18:173-6.

12. Boos CJ, Lip GY. Assesment of mean platelet volume in coronary artery disease- What does it mean? Thrombo Res 2007;120:11-3.

13. Zuberi BF, Akhtar N, Afsar S. Comparison of mean platelet volume in patients with diabetes mellitus impaired fasting glucose and non diabetic subjects. Singapore Med J.2008;49(2):114-116.

14. Dindar S, Cinemre H, Sengul E et al. Volumen Medio de Plaquetas está Asociado con el Control Glucémico y la Retinopatía en Pacientes con Diabetes Mellitus Tipo 2.West Indian Med J. 2013; 62 (6): 519.

15. Khandekar MM, Khurana AS, Deshmukh S D et al. Platelet volume indices in patients with coronary artery disease and acute myocardial infarction: an Indian scenario. J Clin Pathol. 2006;59:146-149.

16. Bath $\mathrm{P}$, Algert $\mathrm{C}$, Chapman $\mathrm{N}$ et al. Association of mean platelet volume with risk of stroke among 3134 individuals with history of cerebrovascular diseases - Stroke. American heart association J. 2004;35:622-626.

17. Khuwaja AK, Rafique G, White F, Azam SI. Macrovascular complications and their associated factors among persons 
with type 2 diabetes in Karachi, Pakistan- a multi-center study. J Pak Med Assoc. 2004;54(2):60-66.

18. Ozder A, Eker H. Investigation of mean platelet volume in patients with type 2 diabetes mellitus and in subjects with impaired fasting glucose: a cost-effective; tool in primary health care? Int J Clin Exp Med. 2014;7(8):2292-2297.

19. Ulutas K, Dokuyucu R, Sefil F et al. Evaluation of mean platelet volume in patients with type 2 diabetes mellitus and blood glucose regulation: a marker for atherosclerosis?. Int J Clin Exp Med. 2014;7(4):955-961.

20. Sari M, Lindarto D, Gatot D. Mean platelet volume increases in proliferative retinopathy among diabetes mellitus subjects. Univ Med. 2014;33:43-8.
21. Agrawal B, Manchanda B, Garg A et al. Mean platelet volume in acute myocardial infarction: a case-controlled study. Journal of Cardiovascular Research.2015;1:4.

22. Sharma M, Narang S, Neema s et al. Study of altered platelet morphology with changes in glycaemic status. Int J Res Med Sci. 2016;4(3):757-761.

23. Khode V, Sindhur J, Kanbur D et al. Mean platelet volume and other platelet volume indices in patients with stable coronary artery disease and acute myocardial infarction: A case control study. J Cardiovasc Dis Res. 2012;3:272-5.

24. Yilmaz T, Yilmaz A. Relationship between Altered Platelet Morphological Parameters and Retinopathy in Patients with Type 2 Diabetes Mellitus. Journal of Ophthalmology. 2016;4:1-5.

*Corresponding author:

Dr. Sushma K L, \#202 6th A main 10th A cross A sector Yelahanka new town Bangalore 560106 (India)

Phone: +91 08028460467 / 7259517494 / 9844680847

Email: sushma.kenkere@gmail.com

Date of Submission : 27.01.2017

Date of Acceptance : 16.07.2017

Financial or other Competing Interests: None.
Date of Publication : 30.10.2017 